\section{Case Reports in Ophthalmology}

Case Rep Ophthalmol 2018;9:49-53

\title{
Repair of Traumatic Rhegmatogenous Retinal Detachment Combined with Congenital Falciform Retinal Detachment
}

\author{
Fukutaro Mano Kuo-Chung Chang Tomiya Mano \\ Suita Tokushukai Hospital Eye Center, Suita, Japan
}

\section{Keywords}

Encircling scleral buckling · Falciform retinal detachment - Persistent fetal vasculature .

Vitrectomy

\begin{abstract}
Purpose: To report a case of surgical repair of traumatic rhegmatogenous retinal detachment combined with congenital falciform retinal detachment (FRD). Methods: A retrospective case report. Results: A 36-year-old man with traumatic rhegmatogenous retinal detachment complicating a previously known FRD was successfully treated despite residual FRD following pars plana lensectomy, vitrectomy, and encircling scleral buckling. His best corrected visual acuity improved from hand motion at $50 \mathrm{~cm}$ to $20 / 1,000$. Conclusion: We concluded that the root of the FRD is susceptible to trauma because of the contraction of fibrovascular tissue. The early intervention of modern vitrectomy to traumatic rhegmatogenous retinal detachment complicating a previously known FRD is an important consideration for enhanced quality of care and optimal patient outcomes.




\section{Case Reports in Ophthalmology}

\begin{tabular}{l|l}
\hline DOI: $10.1159 / 000485550$ & (c) 2018 The Author(s). Published by S. Karger AG, Basel \\
\hline
\end{tabular} www.karger.com/cop

Mano et al.: Repair of Traumatic Rhegmatogenous Retinal Detachment Combined with Congenital Falciform Retinal Detachment

\section{Introduction}

Falciform retinal detachment (FRD), also referred to as "congenital falciform fold," is often the result of proliferation of fibrovascular tissue and contraction that extends from the optic disc to the peripheral retina. The tissue is usually richly vascular, and this displacement typically induces numerous folds and may cause retinal detachment as a result of strong contraction of the retina anteriorly. FRD is caused by several diseases, including retinopathy of prematurity, familial exudative vitreoretinopathy, persistent fetal vasculature (PFV), Bloch-Sulzberger syndrome, Norrie disease, retinal hemangiomas (Von Hippel disease), and ocular toxocariasis. FRD has also been observed in other general disorders, especially those associated with abnormalities of the central nervous system. FRD caused by retinopathy of prematurity, familial exudative vitreoretinopathy, or Bloch-Sulzberger syndrome is bilateral, while FRD caused by PFV is almost always unilateral [1].

$\mathrm{PFV}$ is a rare congenital developmental malformation of the eye, caused by the failure of regression of the primary vitreous. It is divided into anterior and posterior types and is characterized by the presence of a vascular membrane located behind the lens. Most cases of PFV are sporadic, but it can be inherited as an autosomal dominant or recessive trait [2]. PFV management is based on the extent of anterior and posterior segment involvement. The natural history of PFV is characterized by recurrent intraocular hemorrhage and secondary glaucoma [3].

\section{Case Report}

A 36-year-old man with FRD was diagnosed at another hospital in 2002. FRD had previously been attributed to PFV according to medical records (unilateral, no family history, fullterm birth, and no systemic complications). Post-lenticular opacity was not observed, and he was diagnosed with posterior type PFV. His best corrected visual acuity (BCVA) was 20/2,000 in his right eye. The left eye was normal and the BCVA was 20/20. In September 2016, the patient was referred to our hospital with traumatic (a blunt trauma from hitting a stone) total retinal detachment and vitreous hemorrhage. His BCVA had been reduced to hand motion at $50 \mathrm{~cm}$ and slit-lamp examination confirmed a traumatic cataract, vitreous hemorrhage, and total retinal detachment with FRD (Fig. 1). He exhibited neither orbital injuries nor facial damage. Two weeks after the referral (because he hesitated for the surgery in consideration of poor prognosis), we performed pars plana lensectomy and vitrectomy, encircling scleral buckling, and silicone oil (SO) tamponade. Pars plana lensectomy was performed first because a severe phacodonesis was observed. After the lens removal, vitrectomy was performed. Causative retinal tear was observed at the root of the FRD. Using a bimanual technique, we carefully removed the vitreous hyaloid membrane, which was strongly adhered to the posterior retina. We reattached the retina under perfluorocarbon liquid, and performed endolaser photocoagulation. After the fluid-air exchange, encircling scleral buckling was performed and the vitreous cavity was filled with SO (Fig. 2).

After the surgery, elevated transient intraocular pressure was observed in his right eye, but the pressure was controlled through medical treatments (oral acetazolamide, dorzolamide hydrochloride, and timolol maleate eye drops). The retina was attached under SO tamponade without a recurrent detachment. SO tamponade was removed 3 months after the surgery. Three months after the SO tamponade removal, the retina was reattached despite residual FRD and the patient's BCVA improved to 20/1,000 (Fig. 3). 


\section{Case Reports in Ophthalmology}

\begin{tabular}{l|l}
\hline DOI: $10.1159 / 000485550$ & (C) 2018 The Author(s). Published by S. Karger AG, Basel
\end{tabular} www.karger.com/cop

Mano et al.: Repair of Traumatic Rhegmatogenous Retinal Detachment Combined with Congenital Falciform Retinal Detachment

\section{Discussion}

Shima et al. [4] reported a case of newly developed FRD in a patient with Norrie disease treated by lens-sparing vitrectomy. Ikeda et al. [5] reported 2 cases of FRD combined with rhegmatogenous retinal detachment that was repaired by vitrectomy. In these cases, causative holes were detected along the FRD slope, and were considered to be the posterior pole. The FRD was successfully treated by removing the posterior vitreous hyaloid membrane, which was thick and strongly adhered to the retina. In the present case, the causative tear existed near the root of the FRD. We concluded that this area is susceptible to trauma because of the contraction of fibrovascular tissue.

Early-phase FRD is difficult to treat because it has anatomical anomalies caused by severe retinal dysplasia. However, several case studies have demonstrated the success of vitrectomy to treat combined FRD, which has normal vessels developing in the peripheral retina. Some reports have emphasized that patients with combined anterior and posterior PFV can achieve functional visual acuities when treated with modern vitreoretinal techniques and aggressive amblyopic therapy [6, 7]. In the present case, the patient had FRD that was diagnosed as posterior PFV and his visual acuity remained constant prior to suffering the trauma. Therefore, we hypothesized that he would regain visual acuity with retinal detachment repair. Indeed, the patient's complicated retinal detachment was repaired following pars plana lensectomy and vitrectomy, and his functional visual acuity was salvaged. Thus, the early intervention of modern vitrectomy for traumatic rhegmatogenous retinal detachment complicating a previously known FRD is an important consideration for enhanced quality of care and optimal patient outcomes.

\section{Statement of Ethics}

All study procedures were conducted in accordance with the Declaration of Helsinki, and informed consent was obtained from the patient after approval from the Institutional Review Board. The patient was Japanese.

\section{Disclosure Statement}

None of the authors have any financial/conflicting interests to disclose.

\section{References}

1 Reese AB: Persistent hyperplastic primary vitreous. The Jackson Memorial Lecture. Am J Ophthalmol 1955;40:317-331.

2 Shastry BS: Persistent hyperplastic primary vitreous: congenital malformation of the eye. Clin Exp Ophthalmol 2009;37:884-890.

-3 Cerón 0, Lou PL, Kroll AJ, et al: The vitreo-retinal manifestations of persistent hyperplastic primary vitreous (PHPV) and their management. Int Ophthalmol Clin 2008;48:53-62.

-4 Shima C, Kusaka S, Kondo H, et al: Lens-sparing vitrectomy effective for reattachment of newly developed falciform retinal detachment in a patient with Norrie disease. Arch Ophthalmol 2009;127:579-580. 


\section{Case Reports in Ophthalmology}

(c) 2018 The Author(s)
www.karger.com/cop

Mano et al:: Repair of Traumatic Rhegmatogenous Retinal Detachment Combined with Congenital Falciform Retinal Detachment

5 Ikeda T, Fujikado T, Tano Y: Combined tractional rhegmatogenous retinal detachment in familial exudative vitreoretinopathy associated with posterior retinal holes: surgical therapy. Retina 1998;18:566-568.

6 Mittra RA, Huynh LT, Ruttum MS, et al: Visual outcomes following lensectomy and vitrectomy for combined anterior and posterior hyperplastic primary vitreous. Arch Ophthalmol 1998;116:11901194.

7 Dass AB, Trese MT: Surgical results of persistent hyperplastic primary vitreous. Ophthalmology 1999;106:280-284.

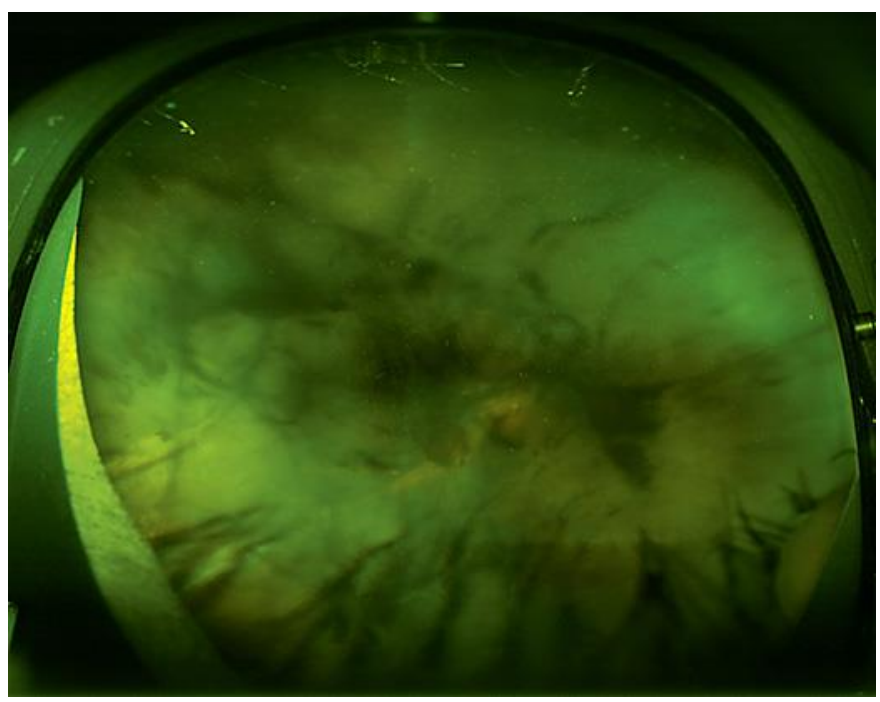

Fig. 1. Preoperative fundus photograph acquired at the first referral by $200 \mathrm{Tx}\left(\mathrm{Optos}^{\circledR}\right)$ : dense vitreous hemorrhage and total retinal detachment are shown.

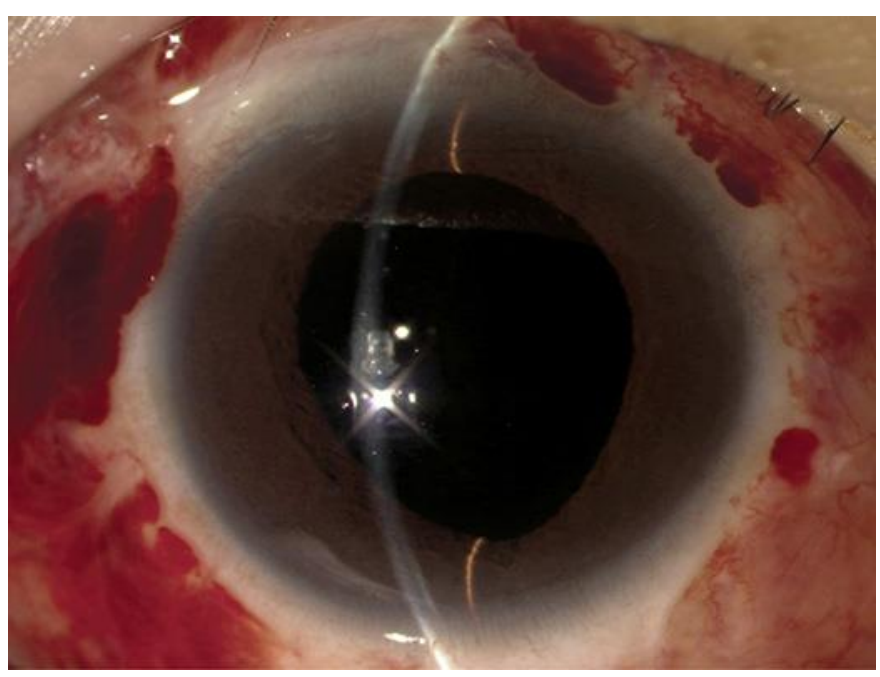

Fig. 2. Anterior segment 14 days after the surgery: clear cornea and aphakia with no inflammation of the anterior chamber is shown. Encircling scleral buckling was performed. 
Case Reports in
Ophthalmology

Case Rep Ophthalmol 2018;9:49-53

DOI: $10.1159 / 000485550$

(c) 2018 The Author(s). Published by S. Karger AG, Basel www.karger.com/cop

Mano et al.: Repair of Traumatic Rhegmatogenous Retinal Detachment Combined with Congenital Falciform Retinal Detachment

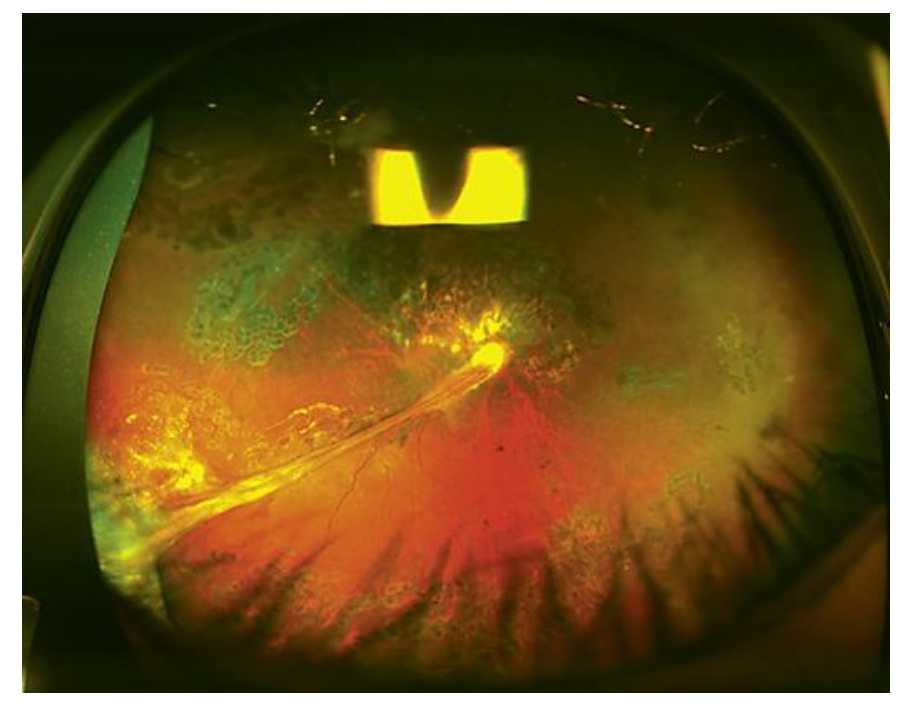

Fig. 3. Postoperative fundus photograph acquired 3 months after the SO removal by 200Tx (Optos $\left.{ }^{\circledR}\right)$ : retina was attached despite residual FRD without SO. 